\title{
Association of albumin or protamine to lipoplexes: enhancement of transfection and resistance to serum
}

H. Faneca ${ }^{1}$

S. Simões ${ }^{1,2}$

M. C. Pedroso de Lima ${ }^{1,3 *}$

${ }^{1}$ Center for Neuroscience and Cell

Biology, University of Coimbra, 3000

Coimbra, Portugal

${ }^{2}$ Laboratory of Pharmaceutical Technology, Faculty of Pharmacy, University of Coimbra, 3000

Coimbra, Portugal

${ }^{3}$ Department of Biochemistry, Faculty of Sciences and Technology, University of Coimbra, 3000

Coimbra, Portugal

*Correspondence to: M. C. Pedroso de Lima, Center for Neuroscience and Cell Biology, University of Coimbra, 3000 Coimbra, Portugal. E-mail: mdelima@ci.uc.pt
Received: 26 June 2003

Revised: 5 November 2003

Accepted: 13 November 2003

\begin{abstract}
Background The successful application of gene therapy depends on the availability of carriers to efficiently deliver genetic material into target cells. Such efficacy is strongly related to key parameters including serum resistance and protection of DNA.
\end{abstract}

Methods The complexes were tested in terms of their biological activity, in the absence or presence of serum, by following transfection activity. Interaction with plasma proteins was evaluated by immunoblotting, while cytotoxicity was assessed by the Alamar Blue assay. Extent of DNA protection was determined both by using ethidium bromide intercalation and DNase I digestion assays.

Results Our results show that, depending on the charge ratio and on the lipid composition, albumin and protamine can be used (either individually or co-associated) to generate cationic liposome/DNA complexes fulfilling in vivo requirements, while exhibiting high levels of transfection activity. In the present work a novel cationic lipid was tested. It was demonstrated that 1-palmitoyl-2-oleoyl-sn-glycero-3-ethylphosphocholine (EPOPC):cholesterol (Chol) liposomes constitute a very promising carrier for gene delivery as illustrated by their enhancing effect on transfection, as compared with DOTAP-containing liposomes. Moreover, the biological activity of EPOPCcontaining complexes is significantly improved upon association of albumin, even in the presence of $60 \%$ serum (namely for the 4/1 lipid/DNA charge ratio). Nevertheless, our studies also show that transfection activity mediated by DOTAP-containing complexes can be significantly enhanced upon precondensation of DNA with protamine.

Conclusions Co-association of HSA and protamine to lipoplexes ensures a high degree of DNA protection and results in high levels of transfection activity even in the presence of serum. Copyright $\odot 2004$ John Wiley \& Sons, Ltd.

Keywords lipoplexes; albumin; protamine; gene delivery; plasma protein interaction; serum resistance; DNA protection

\section{Introduction}

Efficient gene delivery into target cells is a critical issue for the success of gene therapy approaches. Although many efforts have been made to develop efficient non-viral gene delivery systems, their transfection ability has still to be 
improved. Cationic liposome/DNA complexes, also called lipoplexes, have become the most applied devices in studies aimed at developing appropriate non-viral gene delivery systems $[1,2]$. These complexes have proven to be promising approaches in transfecting cells in tissue culture. However, despite this extensive work in recent years, which has resulted in remarkable progress culminating in the use of cationic liposome/DNA complexes in clinical trials, their in vivo efficiency is still unsatisfactory [3]. This low efficiency in vivo is due to some limitations that are associated with these systems, like their poor levels of transfection as compared with viral vectors, and the considerable reduction of their biological activity by serum components [4-6]. However, the potential advantages of these systems over viral vectors prompted investigators to optimise their performance by developing novel formulations. Much effort has been devoted to the synthesis of new cationic lipids that are serum-resistant, selection of different helper lipids and to the use of DNA-condensing agents such as polyamines and protamines aimed at improving the stability of the complexes. Association of proteins or fusogenic peptides has also been show to enhance their biological activity [7-13].

Besides DOTMA and DOTAP, two of the most popular cationic lipids, numerous new lipids have become commercially available for transfection purposes. One of them is EPOPC, a cationic analogue of phosphatidylcholine, consisting only of normal cellular metabolites linked with ester bonds, hence exhibiting a low toxicity and being well suited for clinical applications involving gene therapy $[3,14,15]$. Most of the cationic liposomes that have been used for transfection are composed of both cationic and neutral helper lipids. Helper lipids are known to affect various properties of cationic liposome/DNA complexes and to play a very important role in mediating intracellular gene transfer. Considering intravenous application, when cholesterol was substituted for DOPE, transfection activity was significantly improved. This is probably explained by the difference in the stability between DOPE and cholesterolcontaining lipoplexes in the presence of serum $[7,8,16]$.

Besides lipid composition, the incorporation of other components in the complexes may also be very important in the development of efficient gene delivery systems. It has already been shown that condensation of DNA with protamine sulfate confers DNA protection and improves nuclear translocation of DNA, thus enhancing gene expression [17-20]. On the other hand, coating cationic liposomes with albumin, the most abundant plasma protein, was revealed to be a promising strategy to overcome the undesired interactions between cationic liposome/DNA complexes and serum components. Moreover, our previous observations indicated that association of albumin to the complexes enhances their biological activity by promoting both internalisation of the complexes and intracellular delivery of DNA [21-24].

In this study, we have combined different strategies aimed at obtaining stable complexes in biological fluids and exhibiting high transfection activity. These include the use of different lipid compositions, pre-condensation of DNA with protamine and association of albumin to the lipoplexes. We have evaluated whether the transfection activity of the resulting complexes could be correlated with the degree of protection conferred to DNA and with the extent of lipoplex interaction with serum components. Overall, these data may be of great relevance for future in vivo applications.

\section{Materials and methods}

\section{Preparation of cationic liposomes and their complexes with DNA}

Small unilamellar cationic liposomes (SUV) were prepared by extrusion of multilamellar liposomes (MLV) composed of a $1: 1$ (mole ratio) mixture of 1,2dioleoyl-3-(trimethylammonium)propane (DOTAP) and dioleoylphosphatidylethanolamine (DOPE) or cholesterol (Chol) and from a $1: 1$ (mole ratio) mixture of 1-palmitoyl-2-oleoyl-sn-glycero-3-ethylphosphocholine (EPOPC) and Chol. Briefly, lipids (Avanti Polar Lipids, Alabaster, $\mathrm{AL}, \mathrm{USA}$ ) dissolved in $\mathrm{CHCl}_{3}$ were mixed at the desired molar ratio and dried under vacuum in a rotatory evaporator. The dried lipid films were hydrated with deionised water to a final lipid concentration of $6 \mathrm{mM}$ and the resulting MLV were then sonicated, for $3 \mathrm{~min}$, and extruded, 21 times, through two stacked polycarbonate filters of $50 \mathrm{~nm}$ pore diameter using a Liposofast device (Avestin, Toronto, Canada). The resulting liposomes (SUV) were then diluted five times with deionised water and filter-sterilised utilising $0.22 \mu \mathrm{m}$ pore-diameter filters (Schleicher \& Schuell BioScience, Germany). Lipoplexes were prepared by sequentially mixing $100 \mu \mathrm{l}$ of a HEPESbuffered saline solution (HBS; $100 \mathrm{mM} \mathrm{NaCl,} 20 \mathrm{mM}$ HEPES, pH 7.4) with liposomes (whose volume was dependent on the $(+/-)$ charge ratio) and with $100 \mu 1$ of HBS solution containing $1 \mu \mathrm{g}$ of pCMVluc (VR-1216; a gift from Dr. P. Felgner, Vical, San Diego, CA, USA). The mixture was further incubated for $15 \mathrm{~min}$ at room temperature. Complexes were also prepared by pre-incubating liposomes with human serum albumin (HSA; $32 \mu \mathrm{g} / \mu \mathrm{g}$ of DNA). This ratio was selected based on previous studies showing that these conditions led to the highest levels of transfection [23]. In parallel, DNA was pre-incubated with protamine at different $\mathrm{w} / \mathrm{w}$ ratios $(0.5,1,2,4 \mu \mathrm{g}$ of protamine/ $\mu \mathrm{g}$ of DNA). In both cases incubations were performed for $15 \mathrm{~min}$, at room temperature. Finally, complexes were obtained by mixing both suspensions and further incubated for $15 \mathrm{~min}$ at room temperature.

\section{Physicochemical characterisation of complexes}

Complexes were characterised with respect to their size using a Coulter N4 Plus (Coulter Corporation, Miami, FL, 
USA). The Coulter N4 Plus is a PCS (photon correlation spectroscopy)-based technique which uses autocorrelation spectroscopy of scattered laser light to determine its time-dependent fluctuations resulting from the Brownian motion of particles in suspension. The light intensity scattered at a given angle is detected by a photo-multiplier whose output current is passed to an autocorrelator, which analyses time dependence, determining the rate of diffusion or Brownian motion of the particles and hence their size. The detection angle is fixed at $90^{\circ}$. Complexes were prepared immediately before analysis. All complexes showed a polymodal size distribution.

\section{Cells}

COS-7 cells (American Type Culture Collection, Rockville, $\mathrm{MD}$, USA) were maintained at $37^{\circ} \mathrm{C}$, under $5 \% \mathrm{CO}_{2}$, in Dulbecco's modified Eagle's medium-high glucose (DMEM-HG; Irvine Scientific, Santa Ana, CA, USA) supplemented with $10 \%(\mathrm{v} / \mathrm{v})$ heat-inactivated fetal bovine serum (FBS; Sigma, St. Louis, MO, USA), penicillin $(100 \mathrm{U} / \mathrm{ml})$, streptomycin $(100 \mu \mathrm{g} / \mathrm{ml})$ and L-glutamine (4 mM). For transfection, $0.4 \times 10^{5}$ COS-7 cells were seeded in $1 \mathrm{ml}$ of medium in 48-well culture plates and used at 50-70\% confluence.

\section{Transfection activity}

Transfection activity mediated by the complexes was evaluated as described previously [25,26]. Cells were rinsed twice with serum-free medium and then covered with $0.3 \mathrm{ml}$ of DMEM-HG (without serum, unless indicated otherwise) before lipid-based complexes were added. The complexes were added gently to cells in a volume of $0.2 \mathrm{ml}$ per well. After $4 \mathrm{~h}$ incubation (in $5 \%$ $\mathrm{CO}_{2}$ at $37^{\circ} \mathrm{C}$ ) the medium was replaced with DMEM-HG containing $10 \% \mathrm{FBS}$, and the cells were incubated for a further $48 \mathrm{~h}$. The cells were then washed twice with phosphate-buffered saline (PBS) and $100 \mu \mathrm{l}$ of lysis buffer (1 mM DTT, $1 \mathrm{mM}$ EDTA, $25 \mathrm{mM}$ Tris-phosphate ( $\mathrm{pH}$ 7.8), $8 \mathrm{mM} \mathrm{MgCl}_{2}, 15 \%$ glycerol, $1 \%$ (v/v) Triton X-100) were added to each well. The level of gene expression in the lysates was evaluated by measuring light production by luciferase in a Mediators PhL luminometer (Mediators Diagnostika, Vienna, Austria). The protein content of the lysates was measured by the Dc protein assay reagent (Bio-Rad, Hercules, CA, USA) using bovine serum albumin (BSA) as the standard. The data were expressed as relative light units (RLU) of luciferase per mg of total cell protein.

\section{Interaction of lipid-based complexes with plasma proteins}

The assay for determining the interaction of cationic complexes with plasma proteins is based on the retention of the complexes by a $200 \mathrm{~nm}$ Anopore membrane (Whatman, Kent, UK) and using the protocol described by Ogris et al. [5]. Following their preparation, the complexes were incubated with $2 \%$ of human plasma for $30 \mathrm{~min}$ at $37^{\circ} \mathrm{C}$. The membrane of microcentrifuge tube filters (Whatman, Kent, UK; $200 \mathrm{~nm}$ Anopore membrane) was saturated with $500 \mu \mathrm{BSA}(1 \mathrm{mg} / \mathrm{ml})$ to reduce unspecific interaction of plasma proteins with the membrane and was washed three times with $500 \mu \mathrm{l}$ of HBS solution. The mixture of complexes and plasma was applied onto the membrane, filtered by centrifugation at $10000 \mathrm{~g}$ and washed three times with $500 \mu \mathrm{l} \mathrm{HBS}$. The residue (complex-bound plasma proteins) was eluted with $100 \mu \mathrm{l}$ HBS containing 5\% (w/v) SDS. Samples (eluate) and control (HBS solution treated in the same way) were diluted ten times with HBS and twice with sample buffer (100 mM Tris-HCl (pH 6.8), 4\% (w/v) SDS, $20 \%(\mathrm{v} / \mathrm{v})$ glycerol, $0.2 \%(\mathrm{w} / \mathrm{v})$ bromphenol blue), and the associated proteins denaturated in boiling water for $3 \mathrm{~min}$. Aliquots of the treated samples and control were then applied onto a $7.5 \%$ SDS polyacrylamide gel and separated at $180 \mathrm{~V}$ for $1 \mathrm{~h}$ in a Mini-PROTEAN II electrophoresis cell (Bio-Rad). For immunological identification of the protein a gel was blotted onto a Hybond P (PVDF) membrane via semidry blotting (Bio-Rad) at $15 \mathrm{~V}$ for $10 \mathrm{~min}$. Unspecific binding was blocked by incubating the blot with $5 \%$ milk powder in TBST (2.5 mM Tris- $\mathrm{HCl}$ (pH 7.6), $15 \mathrm{mM} \mathrm{NaCl,} \mathrm{0.1 \%}$ Tween 20) for $2 \mathrm{~h}$ at room temperature (RT). The blots were incubated for $1 \mathrm{~h}$ at RT with the antibody solution (antibodies were diluted in TBST) containing rabbit anti-human complement $\mathrm{C}_{3}$ (Serotec, Oxford, UK) $1: 4000$. As second antibody, an alkaline phosphatase (AP) conjugate with goat-anti-rabbit IgG (Amersham Pharmacia Biotech, Uppsala, Sweden) 1:20000 was used. After $1 \mathrm{~h}$ incubation at RT the blots were washed several times with TBST and incubated with ECF (alkaline phosphatase substrate; $20 \mu \mathrm{l}$ of $\mathrm{ECF} / \mathrm{cm}^{2}$ of membrane) for $5 \mathrm{~min}$ at RT and then submitted to fluorescence detection at $570 \mathrm{~nm}$ using a Storm-860 (Molecular Dynamics, Sunnyvale, CA, USA).

\section{Cell viability assay}

Following transfection under the different experimental conditions, cell viability was accessed by a modified Alamar Blue assay [27]. The assay measures the redox capacity of the cells due to the production of metabolites as a result of cell growth and allows determination of viability over the culture period without the detachment of adherent cells. Briefly, $1 \mathrm{ml}$ of $10 \%$ (v/v) Alamar Blue dye in complete DMEM-HG medium was added to each well $45 \mathrm{~h}$ following the initial transfection period $(4 \mathrm{~h})$. After $3 \mathrm{~h}$ of incubation at $37^{\circ} \mathrm{C}, 200 \mu \mathrm{l}$ of the supernatant were collected from each well and transferred to 96-well plates. The absorbance at 570 and $600 \mathrm{~nm}$ was measured in a Mediators PhL luminometer (Mediators Diagnostika). Cell viability (as a percentage of control cells) was calculated according to the formula $\left(A_{570}-A_{600}\right)$ of treated cells $\times 100 /\left(A_{570}-A_{600}\right)$ of control cells. 


\section{Ethidium bromide intercalation assay}

The accessibility of ethidium bromide to the DNA associated with the complexes was evaluated at $37^{\circ} \mathrm{C}$, for $2 \mathrm{~min}$, in a SPEX Fluorolog 2 fluorometer (SPEX Industries, Edison, NJ, USA) as previously described [26]. Briefly, EtBr fluorescence was read at excitation and emission wavelengths of 518 and $605 \mathrm{~nm}$, respectively, using $1 \mathrm{~mm}$ excitation and $2 \mathrm{~mm}$ emission slits. The sample chamber was equipped with a magnetic stirring device, and the temperature was controlled with a thermostatted circulating water bath. The fluorescence scale was calibrated such that the initial fluorescence of $\mathrm{EtBr}(20 \mu \mathrm{l}$ of a $2.5 \mathrm{mM}$ solution added to a cuvette containing $2 \mathrm{ml}$ HBS solution) was set at residual fluorescence. The value of fluorescence obtained upon addition of $1 \mu \mathrm{g}$ DNA (control) was set as $100 \%$. Complexes ( $1 \mu \mathrm{g}$ DNA) were added to the cuvette containing $2 \mathrm{ml}$ HBS solution followed by addition of $20 \mu \mathrm{l}$ of EtBr. The amount of DNA available to interact with the probe was calculated by subtracting the values of residual fluorescence from those obtained for the samples and expressed as the percentage of the control.

\section{Resistance to DNase I action}

Resistance of complexes to DNase I (Sigma) was determined by electrophoresis and spectrofluorimetry. DNase I was maintained in a buffer solution $(50 \mathrm{mM}$ Tris-HCl ( $\mathrm{pH}$ 7.5), $10 \mathrm{mM} \mathrm{MnCl}_{2}, 50 \mu \mathrm{g} / \mathrm{ml} \mathrm{BSA}$ ). Complexes were submitted to DNase I action (10 units DNase $\mathrm{I} / \mu \mathrm{g}$ of DNA), during $30 \mathrm{~min}$ at $37^{\circ} \mathrm{C}$, followed by inactivation of the enzyme upon incubation with 0.5 M EDTA ( $1 \mu \mathrm{l}$ /unit of DNase I). Parallel experiments were performed by incubating samples under the same experimental conditions, except that DNase I was previously inactivated. Electrophoresis was performed in $1 \%$ agarose gel prepared in TBE solution ( $89 \mathrm{mM}$ Tris-buffer ( $\mathrm{pH}$ 8.6), $89 \mathrm{mM}$ boric acid, $2.5 \mathrm{mM}$ EDTA) and containing $1 \mu \mathrm{g} / \mathrm{ml}$ of EtBr. Following incubation of the complexes with DNase I (active or inactive), aliquots corresponding to $200 \mathrm{ng}$ of DNA, to which $5 \mu \mathrm{l}$ of loading buffer $(15 \%(\mathrm{v} / \mathrm{v})$ ficoll $400,0.05 \%(\mathrm{w} / \mathrm{v})$ bromphenol blue, 1\% (w/v) SDS, 0.1 M EDTA, pH 7.8) had been previously added, were placed in the gel. The electrophoresis elapsed, for $1 \mathrm{~h}$ and $45 \mathrm{~min}$, applying a voltage of $100 \mathrm{~V}$ [26].

\section{In vivo transfection}

Gene expression in vivo was assessed by injecting plain lipoplexes and HSA-lipoplexes (both containing EPOPC/cholesterol at a $1: 1$ mole ratio) into 8-weekold mice (CD-1 mice) via the tail vein in a volume of $300 \mu$ l. Plain lipoplexes or HSA-lipoplexes (containing $2.4 \mathrm{mg}$ HSA) were prepared at a charge ratio $(+/-)$ of $4 / 1$ and contained $75 \mu \mathrm{g}$ pCMVluc. The organs were harvested and homogenised $24 \mathrm{~h}$ following injection, and luciferase expression in the supernatant was measured in a luminometer (Mediators Diagnostika; www.mediatorsint.com) using a standard curve for luciferase activity.

\section{Results \\ Mean diameter of the lipid-based complexes}

The efficacy of carrier systems to deliver genetic material into target cells is dependent on their physicochemical properties, since these are known to affect their stability and biological activity [28,29].

As illustrated in Table 1, lipoplexes prepared from DOTAP:Chol and EPOPC: Chol cationic liposomes at 2/1 (+/-) charge ratio exhibited larger mean diameters (approximately $1700 \mathrm{~nm}$ ) than lipoplexes prepared with the same composition at $4 / 1(+/-)$ charge ratio. The association of albumin or both albumin and protamine to these complexes resulted in a significant increase in their size. On the other hand, incubation of the different complexes with $60 \%$ of serum led to different changes in their size. For the lipoplexes prepared at the $4 / 1(+/-)$ charge ratio (in the absence of albumin and protamine), incubation with $60 \%$ serum for 30 min resulted in no significant size effect. For the complexes prepared at the same $(+/-)$ charge ratio, but in the presence of albumin or of albumin and protamine, incubation with $60 \%$ serum for $30 \mathrm{~min}$ promoted a significant decrease in their mean diameter. It should be noted that size measurements were performed on control samples containing only $60 \%$ serum, thus allowing the elimination of the contribution of serum components to the mean diameter distribution determined for the different lipoplex preparations (data not shown). For the various conditions tested no major differences were observed when DOTAP was replaced by EPOPC.

\section{Biological activity of the complexes}

Figure 1 illustrates the influence of complex composition and charge ratio on their biological activity. Transfection

Table 1. Mean diameters of lipid-based complexes

\begin{tabular}{lcc}
\hline & $\begin{array}{c}\text { Mean } \\
\text { diameter } \\
(\mathrm{nm})\end{array}$ & $\begin{array}{c}\text { Mean } \\
\text { diameter } \\
(\mathrm{nm}) 60 \% \text { of } \\
\text { serum }\end{array}$ \\
\hline Complexes & $1673( \pm 324)$ & $633( \pm 286)$ \\
DOTAP: Chol/DNA (+/-) (2/1) & $255( \pm 91)$ & $396( \pm 164)$ \\
HSA-DOTAP : Chol/DNA (+/-) (4/1) & $2034( \pm 516)$ & $570( \pm 260)$ \\
HSA-DOTAP: Chol/DNA 4P $(+/-)(4 / 1)$ & $2007( \pm 430)$ & $821( \pm 336)$ \\
EPOPC : Chol/DNA (+/-) (2/1) & $1671( \pm 406)$ & \\
EPOPC: Chol/DNA (+/-) (4/1) & $440( \pm 97)$ & $368( \pm 143)$ \\
HSA-EPOPC: Chol/DNA (+/-) (4/1) & $2150( \pm 432)$ & $873( \pm 392)$ \\
HSA-EPOPC: Chol/DNA 4P (+/-) (4/1) & $1923( \pm 568)$ & $448( \pm 112)$ \\
\hline
\end{tabular}

DOTAP: Chol $(1: 1)$ and EPOPC: Chol (1:1) liposomes were prepared as described in 'Materials and methods'. The results represent the mean \pm standard deviation of at least three independent experiments. 
studies showed that the biological activity mediated by lipoplexes was dependent on their charge ratio $(+/-)$ and on their lipid composition, those prepared at $2 / 1(+/-)$ charge ratio being the most active independently of the liposome composition. Among the different formulations, EPOPC : Chol/DNA complexes were those exhibiting the highest levels of transfection for all charge ratios tested.

Figure 1 also shows that association of HSA to DOTAP : Chol/DNA complexes (at the 4/1 (+/-) charge ratio) led to a slight increase in their biological activity, while HSA-associated EPOPC : Chol/DNA complexes exhibited a significantly higher transfection activity for all charge ratios tested as compared with plain lipoplexes. For DOTAP : DOPE complexes, an enhancement was only observed for the $2 / 1(+/-)$ charge ratio. These results showed that the enhancement of transfection activity induced by albumin is dependent on the lipid composition and on the charge ratio of the complexes.

As illustrated in Figure 2, the use of protamine to pre-condense DNA resulted in an enhancement in transfection activity, this effect being dependent on the amount of protamine, on the presence or absence of HSA, on the charge ratio of the complexes, and on the composition of the liposomes. For DOTAP-containing lipoplexes, prepared at $2 / 1(+/-)$ charge ratio, pre-condensation of DNA with increasing amounts of protamine led to a significant enhancement of transfection activity (up to $2 \mu \mathrm{g}$ of protamine/ $\mu \mathrm{g}$ of DNA; Figure $2 \mathrm{~A}$ ). For higher protamine/DNA ratios a significant decrease in luciferase gene expression was observed. It should be emphasised that this enhancing effect of protamine (namely for the optimal condition) was essentially abolished when HSA

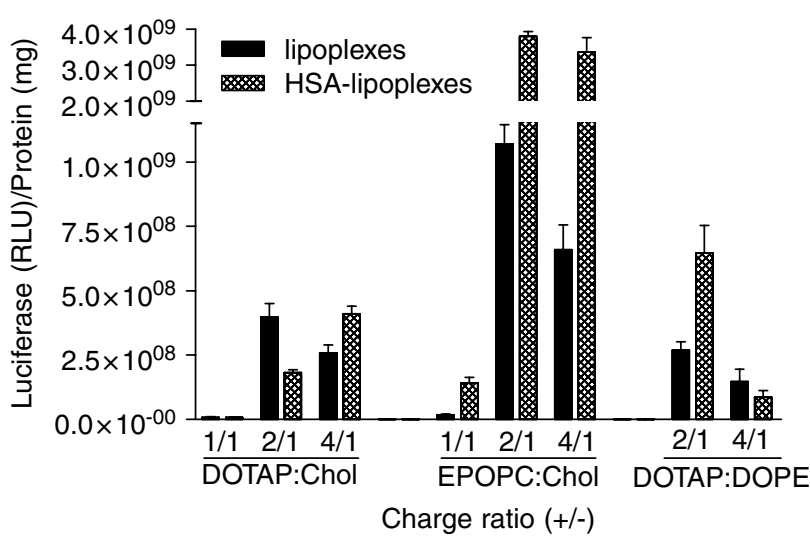

Figure 1. Effect of complex composition and charge ratio $(+/-)$ on luciferase gene expression in COS-7 cells. Cells were rinsed twice with serum-free medium and then covered with $0.3 \mathrm{ml}$ of DME-HG before cationic liposome/DNA complexes were added. The liposomes (DOTAP : Chol, EPOPC: Chol and DOTAP : DOPE), pre-incubated or not with HSA $(32 \mu \mathrm{g} / \mu \mathrm{g}$ of DNA), were complexed with $1 \mu \mathrm{g}$ of pCMVluc at the indicated theoretical lipid/DNA charge ratios. After an incubation for $4 \mathrm{~h}$, the medium was replaced with DME-HG containing 10\% FBS and the cells were further incubated for $48 \mathrm{~h}$. The level of gene expression was evaluated as described in 'Materials and methods'. The data are expressed as RLU of luciferase per $\mathrm{mg}$ of total cell protein (mean \pm standard deviation obtained from triplicates), and are representative of three independent experiments was also present in the complexes. No effect of protamine on transfection was observed when $4 / 1(+/-)$ complexes were used, independently of the presence or absence of HSA.

For EPOPC-containing complexes, prepared both at $2 / 1$ and $4 / 1(+/-)$ charge ratios, a similar pattern on the enhancement of transfection was observed upon addition of protamine, except that the highest values of luciferase gene expression were obtained for the $1 \mu \mathrm{g}$ of protamine/ $\mu \mathrm{g}$ of DNA ratio. Nevertheless, $2 / 1(+/-)$ complexes were more active than $4 / 1(+/-)$ complexes for all the protamine/DNA ratios tested. As opposed to what was observed for DOTAP-containing complexes, the transfection activity mediated by EPOPC-containing complexes was strongly enhanced when albumin was associated to the complexes in the absence of protamine (Figure 2B). This enhancing effect is slightly reduced upon pre-condensation of DNA with $1 \mu \mathrm{g}$ of protamine, levelling off for increasing amounts of protamine.
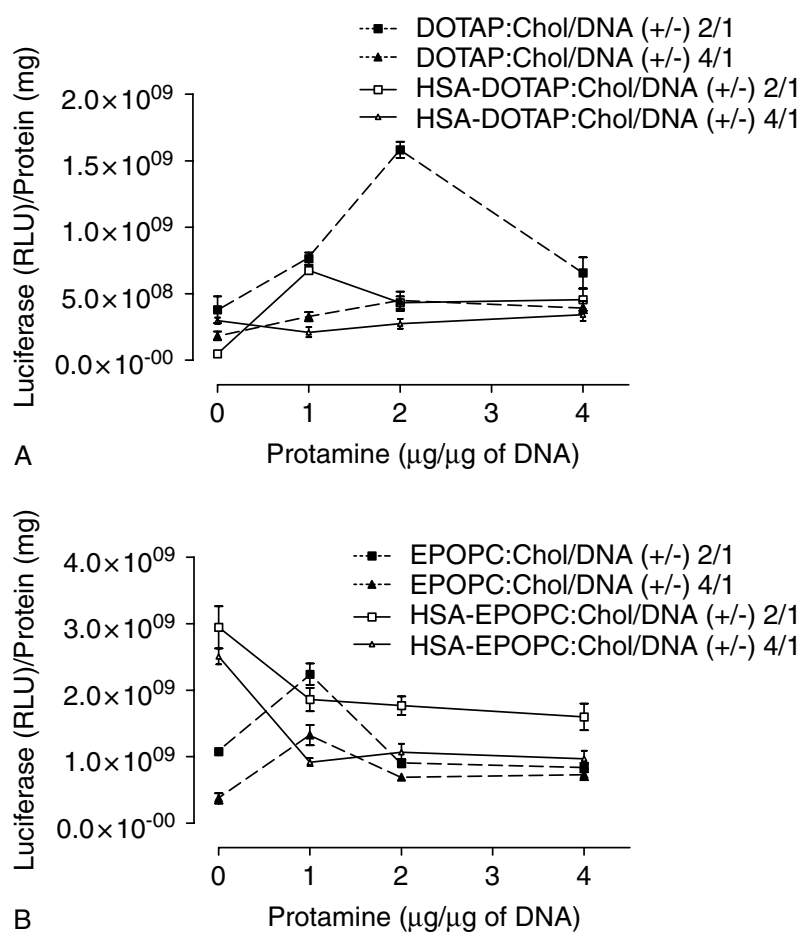

Figure 2. Effect of the amount of protamine on biological activity of complexes in COS-7 cells. Cells were rinsed twice with serum-free medium and then covered with $0.3 \mathrm{ml}$ of DME-HG before cationic liposome/DNA complexes were added: (A) complexes prepared with DOTAP : Chol liposomes; (B) complexes prepared with EPOPC: Chol liposomes. The liposomes, pre-incubated or not with HSA (32 $\mu \mathrm{g} / \mu \mathrm{g}$ of DNA), were complexed with $1 \mu \mathrm{g}$ of pCMVluc, pre-condensed with different amounts of protamine, at the indicated theoretical lipid/DNA charge ratios. After an incubation for $4 \mathrm{~h}$, the medium was replaced with DME-HG containing 10\% FBS and the cells were further incubated for $48 \mathrm{~h}$. The level of gene expression was evaluated as described in 'Materials and methods'. The data are expressed as RLU of luciferase per $\mathrm{mg}$ of total cell protein (mean \pm standard deviation obtained from triplicates), and are representative of three independent experiments 


\section{Effect of serum on transfection activity}

Aiming at predicting the in vivo behaviour of the complexes upon their intravenous administration, transfection studies were performed in the presence of different amounts of serum. As shown in Figure 3, the biological activity of DOTAP : Chol/DNA lipoplexes, prepared at both $2 / 1$ and $4 / 1(+/-)$ charge ratios, decreased as the amount of serum was increased up to $60 \%$. Similar results were observed for EPOPC-containing complexes (data not shown). Taking these findings into account, transfection activity mediated by the other formulations developed in this work was also evaluated in the presence of the highest serum concentration (60\%).

As illustrated in Figure 4, the inhibitory effect of serum on transfection was essentially abolished upon association of albumin to EPOPC-containing complexes prepared at the 4/1 (+/-) charge ratio. Nevertheless, these particular complexes lost their resistance to serum when DNA was pre-condensed with increasing amounts of protamine (1-4 $\mu \mathrm{g}$ of protamine/ $\mu \mathrm{g}$ of DNA). In contrast, association of HSA to DOTAP-containing complexes either at $2 / 1$ or 4/1 charge ratios did not confer any resistance to the inhibitory effect of serum. Surprisingly, however, precondensation of DNA with protamine completely reversed this effect. A significant enhancement of transfection was even observed, as compared with controls (cells transfected in the absence of serum), for the HSADOTAP : Chol/DNA complexes prepared at the 4/1 (+/-) charge ratio. Nevertheless for $2 / 1(+/-)$ complexes the inhibitory effect of serum was maintained, independently of the amount of associated protamine. It should be noted that complexes containing protamine, but prepared in the

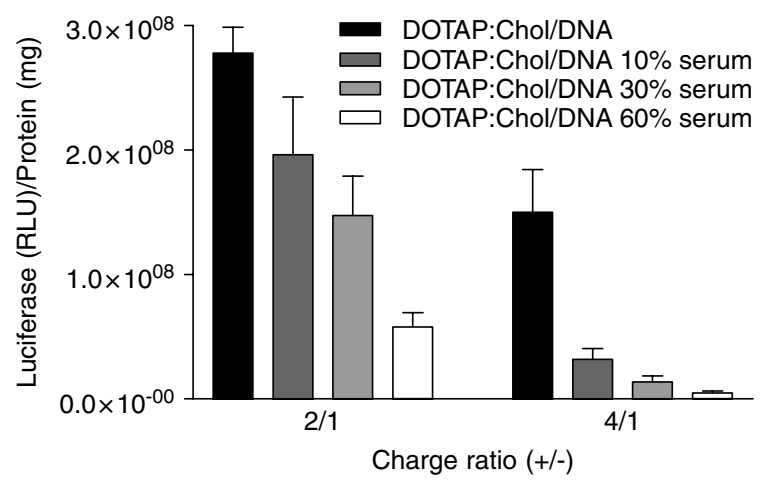

Figure 3. Effect of presence of different serum percentages on luciferase gene expression in COS-7 cells. Cells were covered with $0.3 \mathrm{ml}$ of DME-HG enriched with FBS, in order to obtain a final concentration of 10 or $30 \%$, or with $0.3 \mathrm{ml}$ of FBS, in order to obtain a final concentration of $60 \%$, before lipid/DNA complexes were added. After an incubation for $4 \mathrm{~h}$, the medium was replaced with $1 \mathrm{ml}$ of medium containing $10 \%$ FBS and the cells were further incubated for $48 \mathrm{~h}$. The level of gene expression was evaluated as described in 'Materials and methods'. The data are expressed as the percentage of the RLU of luciferase per $\mathrm{mg}$ of total cell protein of the control (transfection in the absence of serum). The results correspond to the mean \pm standard deviation obtained from triplicates, and are representative of at least two independent experiments absence of HSA, lost most of their biological activity (up to $75 \%$ ) when transfection was carried out in the presence of $60 \%$ serum (data not shown).

\section{Interaction of the complexes with plasma proteins}

Previous reports have already demonstrated that the presence of serum can decrease the transfection activity of the complexes, most likely through interaction with serum proteins [7-9]. In an attempt to clarify this issue, the dependence of the extent of this interaction with certain serum components on the composition of the complexes was investigated by Western blotting. For this purpose, an antibody against C3 human complement protein was used. This protein was investigated because complement activation involving C3 protein is known to play a major role in destabilisation and blood clearance of the complexes [30,31]. Figure 5 shows the bands corresponding to C3 bound to DOTAP: Chol/DNA and EPOPC : Chol/DNA complexes upon their incubation with $2 \%$ human plasma at $37^{\circ} \mathrm{C}$. As can be observed, complexes composed of DOTAP : Chol/DNA $(+/-)(4 / 1)$ prepared with albumin and protamine ( $4 \mu \mathrm{g} / \mu \mathrm{g}$ DNA) bound to the C3 complement protein more extensively than $4 / 1(+/-)$ DOTAP : Chol/DNA complexes containing only albumin or than plain complexes. In the same way, the binding of the C3 complement protein to EPOPC:Chol/DNA $(+/-)(4 / 1)$ complexes containing both albumin and

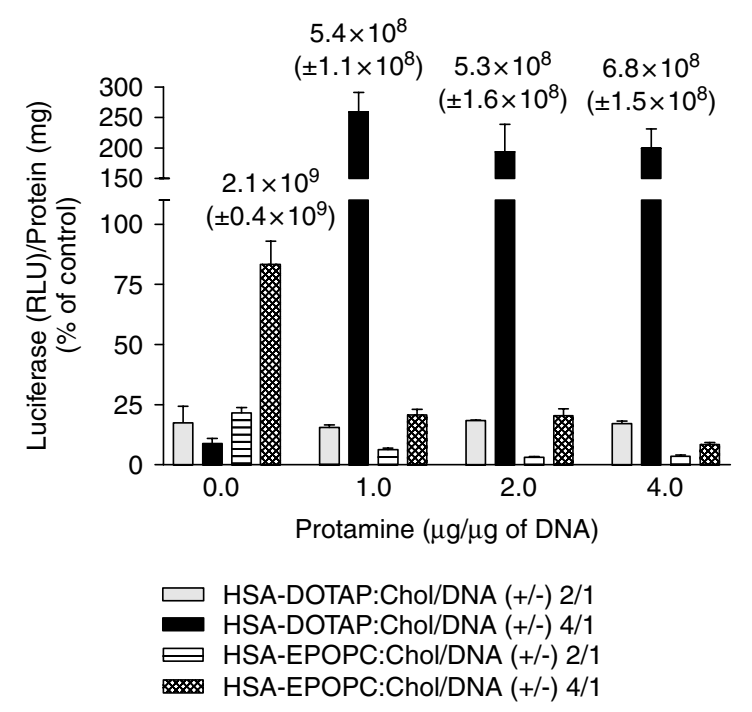

Figure 4. Effect of presence of serum on luciferase gene expression in COS-7 cells. Cells were covered with $0.3 \mathrm{ml}$ of FBS, in order to obtain a final concentration of $60 \%$, before lipid/DNA complexes were added. After an incubation for $4 \mathrm{~h}$, the medium was replaced with $1 \mathrm{ml}$ of medium containing $10 \%$ FBS and the cells were further incubated for $48 \mathrm{~h}$. The level of gene expression was evaluated as described in 'Materials and methods'. The data are expressed as the percentage of the RLU of luciferase per mg of total cell protein of the control (transfection in the absence of serum). The results correspond to the mean \pm standard deviation obtained from triplicates, and are representative of at least three independent experiments 


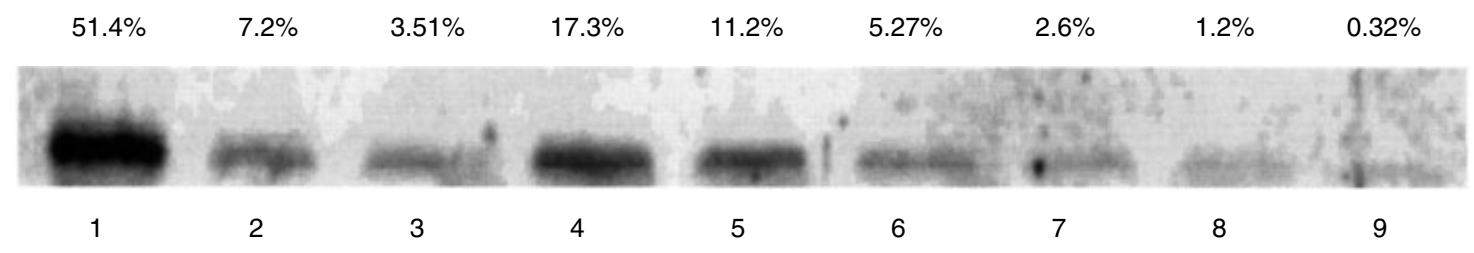

Figure 5. Interaction of cationic liposome/DNA complexes with C3 protein of the human complement. HSA-DOTAP : Chol/DNA-4P $(+/-)(4 / 1)$ (1); HSA-DOTAP : Chol/DNA (+/-) (4/1) (2); DOTAP : Chol/DNA (+/-) (4/1) (3); HSA-EPOPC : Chol/DNA-4P (+/-) (4/1) (4); HSA-EPOPC : Chol/DNA-4P (+/-) (2/1) (5); HSA-EPOPC : Chol/DNA (+/-) (4/1) (6); HSA-EPOPC : Chol/DNA (+/-) $(2 / 1)$ (7); EPOPC : Chol/DNA (+/-) (4/1) (8); control (9). Complexes were incubated at $37^{\circ} \mathrm{C}$, for 30 min, with human plasma and C3 were identified by immunoblotting as described in 'Materials and methods'. Extent of interaction (\%), for each experimental condition, was calculated with respect to the sum of the intensities of the bands for the protein (considered as 100\%). The results are representative of four independent experiments

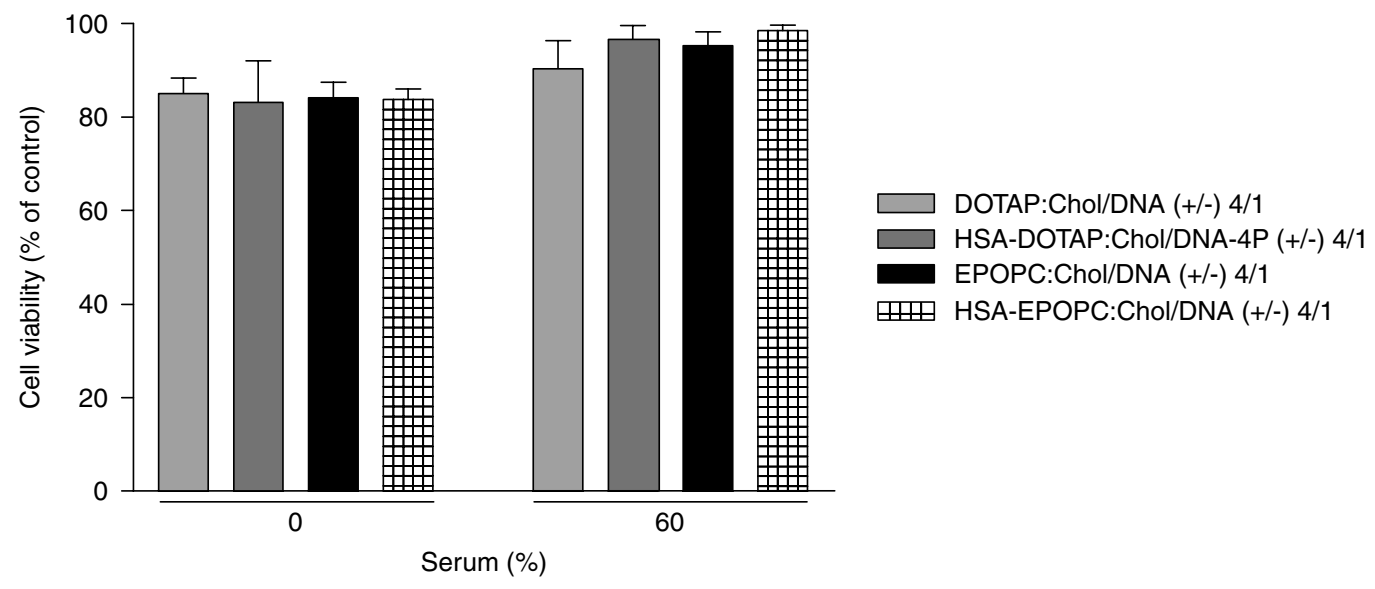

Figure 6. Effect of cationic liposome/DNA complexes on the viability of COS-7 cells. Cells were rinsed twice with serum-free medium and then covered with $0.3 \mathrm{ml}$ of DME-HG or with $0.3 \mathrm{ml}$ of FBS, in order to obtain a final concentration of $60 \%$, before cationic liposome/DNA complexes were added. After an incubation for $4 \mathrm{~h}$, the medium was replaced with DME-HG containing $10 \%$ FBS and the cells were further incubated for $48 \mathrm{~h}$. Cell viability was measured by the Alamar Blue assay as described in 'Materials and methods'. The data are expressed as the percentage of the untreated control cells (mean \pm standard deviation obtained from triplicates), and are representative of two independent experiments

protamine was higher than the binding to complexes with the same lipid composition, either plain or associated only to albumin. It was also observed (Figure 5) that complexes prepared from DOTAP : Chol liposomes bound more protein than those prepared from EPOPC:Chol liposomes and that increasing the $(+/-)$ charge ratio of EPOPC-containing complexes resulted in an increase in the extent of protein binding.

\section{Evaluation of the cytotoxicity induced by the complexes}

Since the application of cationic liposomes is usually associated with some cytotoxicity, we performed cell viability studies for complexes prepared with the highest amount of lipid used in the present work. The results showed that low toxicity (16\%) was induced upon cell incubation with complexes produced with both liposome formulations (DOTAP:Chol and EPOPC:Chol), either associated or not to albumin and protamine in the absence of serum. No cytotoxicity was observed when experiments were performed in the presence of $60 \%$ serum (Figure 6).

\section{Protection of DNA associated to the complexes}

Ethidium bromide is a monovalent DNA-intercalating agent whose fluorescence is dramatically enhanced upon binding to DNA and quenched when displayed by higher affinity compounds or by condensation of the DNA structure. Therefore, this probe has been used to examine the ability of cationic lipids to protect DNA [32]. Figure 7 shows that EtBr fluorescence decreased with increasing the $(+/-)$ charge ratio of the complexes, independently of the cationic liposome formulation used in their preparation. These results clearly indicate that an increase in the amount of cationic liposomes led to a higher degree of DNA condensation and protection as compared with that observed when complexes were prepared at low lipid/DNA charge ratios. The incorporation of albumin into the complexes resulted in a slight increase of the EtBr access to DNA, while an opposite effect was observed when both HSA and protamine were associated to the cationic liposome/DNA complexes. It was also shown that incubation of the complexes with $60 \%$ serum, for $30 \mathrm{~min}$, promoted an increase in the EtBr fluorescence. Nevertheless, under these conditions, all complexes 
prepared at the $4 / 1(+/-)$ charge ratio maintained most of the carried DNA inaccessible to the probe (Figure 7).

In an attempt to demonstrate the degree of DNA protection mediated by the cationic liposomes from degradation by nucleases in vivo, an in vitro DNase I protection assay was performed. Figure 7 also illustrates the results obtained upon incubation of the complexes with active or inactive DNase I. As shown, similar findings were obtained for the extent of DNA degradation induced by DNase I and for the access of EtBr to DNA. DOTAP: Chol/DNA complexes prepared at $4 / 1$ $(+/-)$ charge ratio, with or without albumin, protected most of their DNA, as reflected by the slight difference between the intensity of the bands corresponding to the complexes exposed to inactive and active DNase I (Figure 7A). Differences between the intensity of the bands (complexes incubated with inactive and active DNase I) were practically nonexistent for $4 / 1$ (+/-) DOTAP : Chol/DNA complexes, prepared with both albumin and protamine, indicating their higher capacity to protect DNA (Figure 7A). Similar to $4 / 1(+/-)$ DOTAP : Chol/DNA complexes no major differences were found in the degree of DNA protection for $4 / 1(+/-)$ EPOPC: Chol/DNA complexes, independently of the presence of albumin (Figure 7B). Results on the DNase I resistance mediated by EPOPC-containing complexes when prepared in the presence of protamine are not shown, since the bands corresponding to these complexes either treated with active or inactive DNase I were barely detected (even upon lipid extraction). Nevertheless, data obtained from the assay on the EtBr access to DNA indicate that the presence of protamine only slightly increased protection of DNA.

\section{Discussion}

Although a correlation between in vitro and in vivo transfection studies is not frequently straightforward, exploratory work performed with cell cultures, together with extensive biophysical characterisation of the lipoplexes, provides crucial information for the successful development of novel lipid-based formulations.

In accordance with our previous studies, lipoplexes prepared at $2 / 1(+/-)$ charge ratio present a slightly positive charge [26]. Under this condition, the electrostatic repulsive forces established between the complexes are minimal, thus favouring the formation of large aggregates $[33,34]$. Taking this into account, the smallest complexes were obtained for positively charged complexes (prepared at $4 / 1(+/-)$ charge ratio), a fact attributed to the establishment of repulsive forces, that prevent their aggregation. However, when complexes were prepared at this lipid/DNA charge ratio and associated with albumin and protamine, an increase in the mean diameter was observed, probably due to the neutralising effect of the positive charges of the complexes (conferred by the cationic lipids and protamine) by albumin (which exhibits a net negative charge) [23].
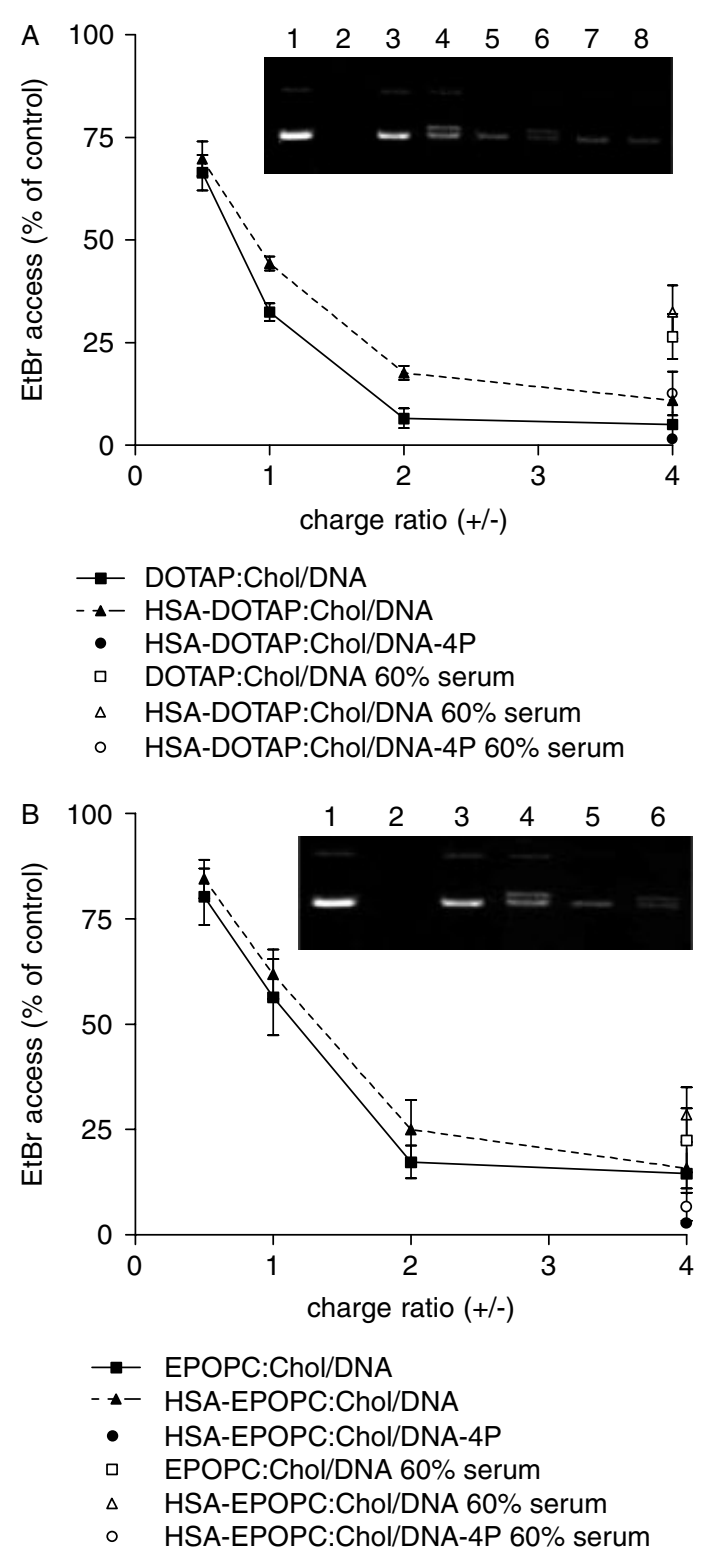

Figure 7. Access of ethidium bromide and resistance to DNase I of DNA associated with the complexes. Complexes prepared with (A) DOTAP : Chol liposomes and (B) EPOPC: Chol liposomes, containing $1 \mu \mathrm{g}$ of DNA, were incubated with EtBr as described in 'Materials and methods'. The amount of DNA available to interact with the probe was calculated by subtracting the values of residual fluorescence from those obtained for the samples and expressed as the percentage of the control. Control corresponds to free DNA, but in the same amount as that associated with the complexes (100\% of EtBr accessibility). The results correspond to the mean \pm standard deviation obtained from independent triplicates. For the resistance to DNase I complexes were incubated with inactive DNase I (odd numbers) or with active DNase I (even numbers), the incubation being performed at $37^{\circ} \mathrm{C}$, for $30 \mathrm{~min}$, using 10 units DNase I per $\mu \mathrm{g}$ of DNA. Control corresponds to the free DNA, but in the same amount as that associated with the complexes. (A) Control (1 and 2); DOTAP : Chol/DNA (+/-) (4/1) (3 and 4); HSA-DOTAP: Chol/DNA (+/-) (4/1) (5 and 6); HSA-DOTAP : Chol/DNA-4P (+/-) (4/1) (7 and 8). (B) Control (1 and 2); EPOPC : Chol/DNA (+/-) (4/1) (3 and 4); HSA-EPOPC : Chol/DNA $(+/-)(4 / 1)$ (5 and 6). Electrophoresis was performed in $1 \%$ agarose gel prepared in TBE solution and containing $1 \mu \mathrm{g} / \mathrm{ml}$ of EtBr as described in 'Materials and methods'. The results are representative of three independent experiments 
Independently of the lipid composition, lipoplexes prepared at the $2 / 1(+/-)$ charge ratio were those exhibiting the highest capacity of transfection. The larger size of these complexes may, at least partially, justify this result, due to their tendency to sediment over the cells, thus promoting cell internalisation. Besides the enhanced interaction of large complexes with cells, it should be considered that these complexes carry a large number of DNA copies, which can also explain the high levels of transfection observed [17,28,35,36]. In addition to the size, the surface charge of the complexes may also play a relevant role, since complexes with a positive zeta potential $(2 / 1$ and $4 / 1(+/-))$ mediated a higher transfection activity than complexes with a negative zeta potential $(1 / 1(+/-))$. This can be due to the extensive interaction of the positively charged complexes with the negatively charged cell membrane [26,32,37]. However, our results indicated, in agreement with previous reports, that the composition of the complexes also plays a very important role in their biological activity $[7,26,38]$. Complexes prepared from the EPOPC:Chol liposomes exhibited a higher biological activity than the complexes prepared from the other liposome formulations tested in the same charge ratio $(+/-)$, in spite of having approximately the same mean diameter and zeta potential. The effect of liposome composition on transfection activity was still more remarkable upon incorporation of albumin and protamine. It should be emphasised that the enhancement of the biological activity induced by these components cannot be attributed to changes in the mean diameter and zeta potential of the complexes.

In the case of albumin, although the exact mechanism of the enhancement of gene delivery and expression by HSA-lipoplexes is not known, previous experiments performed in our laboratory indicate that the endocytotic pathway is involved [23]. In agreement with other reports, these experiments showed that the HSA-lipoplexes could bind non-specifically to cell surface receptors, analogous to scavenger receptors, which in turn mediate their endocytosis, resulting in a transfection enhancement [21-24]. Moreover, albumin can facilitate the escape of DNA from the endocytotic pathway, since albumin has been described as being able to undergo a low $\mathrm{pH}$-induced conformational change, thereby acquiring fusogenic properties [39-41]. However, this capacity of albumin to induce fusion is sensitive to the nature of the lipids, which may explain the dependence of the enhancing effect of albumin on the liposome composition [39]. Thus, the partial protonation of HSA at endosomal $\mathrm{pH}$ and its subsequent interaction with the endosome membrane may be involved in the destabilisation of the latter. This destabilisation may then promote the transbilayer movement (flip-flop) of anionic lipids from the cytoplasmic leaflet of the endosome membrane to the lumenal leaflet [23]. The anionic lipids may then mediate the dissociation of the lipoplex and the entry of the DNA into the cytoplasm, as suggested by Xu and Szoka [32]. It is also possible that the conformational change of albumin, involving a reversible expansion of the protein, reinforces the dissociation of the complexes promoted by lipid flip-flop. All these processes may contribute to the improvement in the biological activity of these complexes induced by albumin.

On the other hand, the enhancing effect of protamine on transfection is probably due to its capacity to condense DNA into a compact structure, which can improve DNA stability and favour its uptake by the cells as well as its nuclear entry [17-19].

Quite frequently, lipofection efficiency decreases drastically by the addition of serum to the transfection medium. Although in in vitro studies inactivation by serum can be circumvented by incubating the cells with the complexes in serum-free medium, this approach cannot obviously be applied in vivo. This shortcoming limits the use of cationic liposomes in in vivo gene delivery, namely considering systemic administration.

Our results showed that cationic liposome/DNA complexes prepared with only protamine at any $(+/-)$ charge ratio lost most of their biological activity in the presence of serum at a final concentration of $60 \%$. This might be explained by the dissociation process of the complexes and/or the formation of large aggregates promoted by serum proteins (such as C3 protein of the complement) that bind to the complexes [38,42]. However, in agreement with other authors, the inhibition of transfection activity depends not only on the extent of binding of serum proteins to the complexes, but also on the complex composition [25,43-45]. In fact, in our study, it was observed that 4/1 (+/-) DOTAP : Chol/DNA complexes with HSA and protamine $(4 \mu \mathrm{g} / \mu \mathrm{g}$ of DNA) and 4/1 (+/-) EPOPC : Chol/DNA complexes with HSA, in spite of binding much larger amounts of serum proteins than complexes prepared in the absence of HSA and protamine, were shown to exhibit resistance to inhibition by serum (up to $60 \%$ ). The observed resistance can be attributed to the ability of certain lipids to overcome the inhibitory effect of serum and/or to different structural reorganisation within the complexes induced by serum, which may be dependent on their composition $[46,47]$. It is also possible that association of some serum components (e.g. proteins) to the complexes promotes their entry into cells via endocytosis and/or plays a role in facilitating intracellular DNA delivery [43,48-50].

Despite the high transfection activity observed in vitro for 4/1 (+/-) DOTAP : Chol/DNA complexes associated with albumin and protamine $(4 \mu \mathrm{g} / \mu \mathrm{g}$ of DNA), the high extent of binding of the C3 protein to these complexes can limit their in vivo use, since this protein is known to play a major role in opsonisation [30,31]. In this regard, albumin-associated EPOPC:Chol/DNA complexes may constitute a promising candidate for in vivo gene delivery, since, in addition to their high biological activity in the presence of serum, their low ability to interact with serum proteins predicts that they will be stable in circulation $[8,51]$. Our preliminary results strongly suggest that albumin-associated lipoplexes are significantly more efficient in mediating in vivo transfection than plain 
lipoplexes (Figure 8). Upon intravenous administration of the complexes, the lung is the organ where the highest levels of transfection have been observed, thus hampering that other organs can be reached. This can be most likely attributed to the large size of the complexes (for in vivo applications, a high concentration of DNA and lipid is needed resulting in an increase in the size of the complexes), indicating that further work is required to optimise their final size. However, the albumin-enhancing effect is particularly relevant in the heart of mice, since in its absence no transfection was observed, this behaviour not being attributed to any retention effect. The preliminary in vivo studies reinforce the potential of EPOPC-containing formulations for in vivo gene delivery, since a 500-fold enhancement in the levels of gene expression in the lung was observed as compared with similar formulations but containing DOTAP [23].

Cytotoxicity results indicate that no major effects on cell viability were observed upon transfection with the different formulations tested. Therefore, differences in transfection activity among the various formulations tested cannot be attributed to cytotoxic effects. It should be noted that the presence of serum totally abolished the low levels of cell toxicity observed. This may be related, not only to better cell growing conditions, but also to the fact that the presence of serum may reduce the strong tendency of the complexes to aggregate and to sediment over the cells [43].

The studies on the access of EtBr to DNA indicate that for the $1 / 2(+/-)$ charge ratio complexes a significant amount of DNA (approximately 75\%) is exposed. Electron microscopy studies performed with cationic liposome/DNA complexes, for which $65 \%$ of DNA was available to EtBr intercalation, indicate that these complexes exhibit a structure where DNA can be detected, suggesting that part of it is free and non-condensed [52]. On the other hand, the observed reduced DNA intercalation of

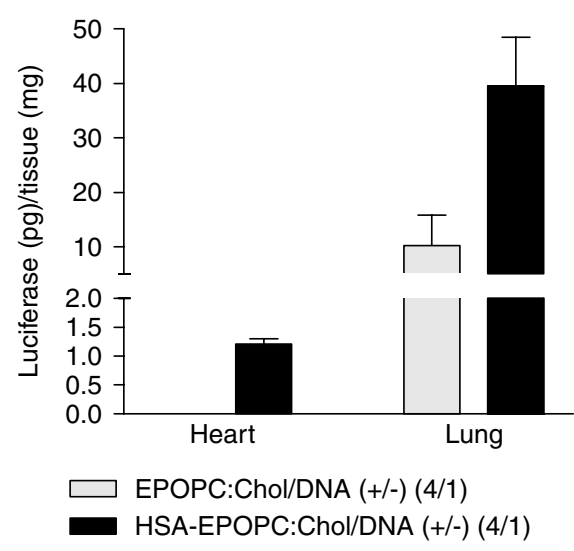

Figure 8. In vivo transfection by plain lipoplexes and HSAlipoplexes. Plain lipoplexes and HSA-lipoplexes (both at a charge ratio $(+/-)$ of $4 / 1$ and containing $75 \mu \mathrm{g}$ pCMVluc) were injected into mice via the tail vein in a volume of $300 \mu$ l. Luciferase gene expression in the lungs and heart was measured $24 \mathrm{~h}$ following injection, and is given as pg of luciferase $/ \mathrm{mg}$ of tissue. The results correspond to the mean \pm standard deviation obtained from three animals
EtBr for complexes prepared at the 2/1 and 4/1 lipid/DNA charge ratios shows that DNA is condensed and almost completely protected. However, association of albumin resulted in a slight decrease of DNA protection. In contrast, incorporation of protamine leads to a reduction in the amount of exposed DNA, showing the condensing and protective capacity of this peptide $[17,18]$. Our findings show that serum proteins bind avidly to some of the complexes tested, which may lead to changes in their structure $[38,47]$. Therefore, the effect of serum on the DNA exposure was evaluated. Our results show that incubation of the complexes with $60 \%$ serum promoted a decrease in DNA condensation, although, for complexes prepared at the $4 / 1(+/-)$ charge ratio, most of the DNA remained protected. This indicates that complexes that are biologically active in the presence of serum maintain most of their DNA protected, independently of the structural reorganisation induced by serum. Studies on DNA protection were complemented using DNase I degradation assays, which are more biologically relevant in demonstrating the ability of the complexes to protect DNA than the EtBr access assay [53]. The results obtained indicate that cationic liposome/DNA complexes prepared at 4/1 (+/-) charge ratio ensure a high degree of DNA protection, this being almost complete when DNA was pre-condensed with protamine.

The ability of the cationic liposome/DNA complexes to exhibit serum resistance and to protect DNA are two of the major requirements for in vivo applications. Although a direct extrapolation of transfection efficiency of the complexes from in vitro to in vivo is not straightforward, in vitro studies of transfection performed in the presence of serum may serve as a predictive model for in vivo transfection efficiency of these systems. In this context, our results suggest that, depending on the charge ratio and on the lipid composition, albumin and protamine can be used to produce cationic liposome/DNA complexes that can efficiently protect DNA, while exhibiting a high biological activity in the presence of serum.

Overall, our results demonstrate that EPOPC constitutes a very promising cationic lipid for gene delivery purposes as illustrated by its enhancing effect on transfection, as compared with DOTAP-containing lipoplexes. Moreover, the biological activity of EPOPC-containing complexes is significantly improved upon association of albumin, even in the presence of $60 \%$ serum (namely for the 4/1 lipid/DNA charge ratio). Nevertheless, our studies also show that transfection activity mediated by DOTAP-containing complexes can be significantly enhanced upon pre-condensation of DNA with protamine. Co-association of HSA and protamine resulted in complexes exhibiting high levels of transfection activity in the presence of serum.

Based on these observations, the formulations developed in this work are promising candidates for in vivo use.

\section{Acknowledgements}

This work was supported by FCT (SFRH/BD/1312/2000) and SAPIENS (36202/99). 


\section{References}

1. Audouy S, Molema G, de Leij L, Hoekstra D. Serum as a modulator of lipoplex-mediated gene transfection: dependence of amphiphile, cell type and complex stability. J Gene Med 2000; 2: 465-476.

2. Mountain A. Gene therapy: the first decade. Trends Biotechnol 2000; 18: 119-128.

3. Pedroso de Lima MC, Simões S, Pires P, Faneca H, Düzgünes N. Cationic lipid-DNA complexes in gene delivery: from biophysics to biological applications. Adv Drug Deliv Rev 2001; 47: 277-294.

4. Remy JS, Kichler A, Mordvinov V, Schuber F, Behr JP. Targeted gene transfer into hepatoma cells with lipopolyamine-condensed DNA particles presenting galactose ligands: a stage toward artificial viruses. Proc Natl Acad Sci U S A 1995; 92: 1744-1748.

5. Ogris M, Brunner S, Schuller S, Kircheis R, Wagner E. PEGylated DNA/transferrin-PEI complexes: reduced interaction with blood components, extended circulation in blood and potential for systemic gene delivery. Gene Ther 1999; 6: 595-605.

6. Dash PR, Read ML, Barrett LB, Wolfert MA, Seymour LW. Factors affecting blood clearance and in vivo distribution of polyelectrolyte complexes for gene delivery. Gene Ther 1999; 6: 643-650.

7. Sternberg B, Hong K, Zheng W, Papahadjopoulos D. Ultrastructural characterization of cationic liposome-DNA complexes showing enhanced stability in serum and high transfection activity in vivo. Biochim Biophys Acta 1998; 1375: 23-35.

8. Liu Y, Mounkes LC, Liggitt HD, et al. Factors influencing the efficiency of cationic liposome-mediated intravenous gene delivery. Nat Biotechnol 1997; 15: 167-173.

9. Lewis JG, Lin KY, Kothavale A, et al. A serum-resistant cytofectin for cellular delivery of antisense oligodeoxynucleotides and plasmid DNA. Proc Natl Acad Sci U S A 1996; 93: 3176-3181.

10. Lee RJ, Huang L. Folate-targeted, anionic liposome-entrapped polylysine-condensed DNA for tumor cell-specific gene transfer. $J$ Biol Chem 1996; 271: 8481-8487.

11. Li S, Huang L. In vivo gene transfer via intravenous administration of cationic lipid-protamine-DNA (LPD) complexes. Gene Ther 1997; 4: 891-900.

12. Mizuarai S, Ono K, You J, Kamihira M, Iijima S. Protaminemodified DDAB lipid vesicles promote gene transfer in the presence of serum. J Biochem (Tokyo) 2001; 129: 125-132.

13. Simões S, Slepushkin V, Pires P, Gaspar R, Pedroso de Lima MC, Düzgünes N. Mechanisms of gene transfer mediated by lipoplexes associated with targeting ligands or $\mathrm{pH}$-sensitive peptides. Gene Ther 1999; 6: 1798-1807.

14. MacDonald RC, Ashley GW, Shida MM, et al. Physical and biological properties of cationic triesters of phosphatidylcholine. Biophys $J$ 1999; 77: 2612-2629.

15. MacDonald RC, Rakhmanova VA, Choi KL, Rosenzweig HS, Lahiri MK. O-ethylphosphatidylcholine: a metabolizable cationic phospholipid which is a serum-compatible DNA transfection agent. J Pharm Sci 1999; 88: 896-904.

16. Templeton NS, Lasic DD, Frederik PM, Strey HH, Roberts DD, Pavlakis GN. Improved DNA: liposome complexes for increased systemic delivery and gene expression. Nat Biotechnol 1997; 15: 647-652.

17. Gao X, Huang L. Potentiation of cationic liposome-mediated gene delivery by polycations. Biochemistry 1996; 35: 1027-1036.

18. Sorgi FL, Bhattacharya S, Huang L. Protamine sulfate enhances lipid-mediated gene transfer. Gene Ther 1997; 4: 961-968.

19. Welz C, Neuhuber W, Schreier H, et al. Nuclear transport of oligonucleotides in HepG2-cells mediated by protamine sulfate and negatively charged liposomes. Pharm Res 2000; 17: $1206-1211$.

20. Tros I, Arangoa MA, Moreno-Aliaga MJ, Duzgunes N. Enhanced gene delivery in vitro and in vivo by improved transferrinlipoplexes. Biochim Biophys Acta 2002; 1561: 209-221.

21. Nunes R, Kiang CL, Sorrentino D, Berk PD. "Albumin-receptor" uptake kinetics do not require an intact lobular architecture and are not specific for albumin. J Hepatol 1988; 7: 293-304.

22. Sorensen KK, Melkko J, Smedsrod B. Scavenger-receptormediated endocytosis in endocardial endothelial cells of Atlantic cod Gadus morhua. J Exp Biol 1998; 201: 1707-1718.

23. Simões S, Slepushkin V, Pires P, Gaspar R, Pedroso de Lima MC, Düzgünes N. Human serum albumin enhances DNA transfection by lipoplexes and confers resistance to inhibition by serum. Biochim Biophys Acta 2000; 1463: 459-469.

24. Christensen EI, Birn H. Megalin and cubilin: multifunctional endocytic receptors. Nat Rev Mol Cell Biol 2002; 3: 256-266

25. Simões S, Slepushkin V, Gaspar R, Pedroso de Lima MC, Düzgünes N. Gene delivery by negatively charged ternary complexes of DNA, cationic liposomes and transferrin or fusigenic peptides. Gene Ther 1998; 5: 955-964.

26. Faneca H, Simões S, Pedroso de Lima MC. Evaluation of lipidbased reagents to mediate intracellular gene delivery. Biochim Biophys Acta 2002; 1567: 23-33.

27. Konopka K, Pretzer E, Felgner PL, Duzgunes N. Human immunodeficiency virus type-1 (HIV-1) infection increases the sensitivity of macrophages and THP-1 cells to cytotoxicity by cationic liposomes. Biochim Biophys Acta 1996; 1312: 186-196.

28. Simões S, Pires P, Düzgünes N, Pedroso de Lima MC. Cationic liposomes as gene transfer vectors: barriers to successful application in gene therapy. Curr Opin Mol Ther 1999; 1: 147-157.

29. Miller CR, Bondurant B, McLean SD, McGovern KA, O'Brien DF. Liposome-cell interactions in vitro: effect of liposome surface charge on the binding and endocytosis of conventional and sterically stabilized liposomes. Biochemistry 1998; 37: 12 875-12 883

30. Bradley AJ, Devine DV. The complement system in liposome clearance: can complement deposition be inhibited? Adv Drug Deliv Rev 1998; 32: 19-29.

31. Plank C, Mechtler K, Szoka FC, Wagner E. Activation of the complement system by synthetic DNA complexes: a potential barrier for intravenous gene delivery. Hum Gene Ther 1996; 7: 1437-1446.

32. Xu Y, Szoka FC. Mechanism of DNA release from cationic liposome/DNA complexes used in cell transfection. Biochemistry 1996; 35: 5616-5623.

33. Mahato RI, Rolland A, Tomlinson E. Cationic lipid-based gene delivery systems: pharmaceutical perspectives. Pharm Res 1997; 14: 853-859.

34. Radler JO, Koltover I, Salditt T, Safinya CR. Structure of DNAcationic liposome complexes: DNA intercalation in multilamellar membranes in distinct interhelical packing regimes. Science 1997; 275: 810-814.

35. Kawaura C, Noguchi A, Furuno T, Nakanishi M. Atomic force microscopy for studying gene transfection mediated by cationic liposomes with a cationic cholesterol derivative. FEBS Lett 1998; 421: 69-72.

36. Bally MB, Harvie P, Wong FM, Kong S, Wasan EK, Reimer DL. Biological barriers to cellular delivery of lipid-based DNA carriers. Adv Drug Deliv Rev 1999; 38: 291-315.

37. Felgner PL, Gadek TR, Holm M, et al. Lipofection: a highly efficient, lipid-mediated DNA-transfection procedure. Proc Natl Acad Sci U S A 1987; 84: 7413-7417.

38. Li S, Tseng WC, Stolz DB, et al. Dynamic changes in the characteristics of cationic lipidic vectors after exposure to mouse serum: implications for intravenous lipofection. Gene Ther 1999; 6: $585-594$

39. Schenkman S, Araujo PS, Dijkman R, Quina FH, Chaimovich H. Effects of temperature and lipid composition on the serum albumin-induced aggregation and fusion of small unilamellar vesicles. Biochim Biophys Acta 1981; 649: 633-647.

40. Garcia A, Shenkman S, Araujo PS, Chaimovich H. Fusion of small unilamellar vesicles induced by bovine serum albumin fragments. Brazil J Med Res 1983; 16: 89-96.

41. Wilschut J, Hoekstra D. Membrane fusion: lipid vesicles as a model system. Chem Phys Lipids 1986; 40: 145-166.

42. Li S, Rizzo MA, Bhattacharya S, Huang L. Characterization of cationic lipid-protamine-DNA (LPD) complexes for intravenous gene delivery. Gene Ther 1998; 5: 930-937.

43. Yang JP, Huang L. Overcoming the inhibitory effect of serum on lipofection by increasing the charge ratio of cationic liposome to DNA. Gene Ther 1997; 4: 950-960.

44. Crook K, Stevenson BJ, Dubouchet M, Porteous DJ. Inclusion of cholesterol in DOTAP transfection complexes increases the delivery of DNA to cells in vitro in the presence of serum. Gene Ther 1998; 5: 137-143.

45. Audouy S, Hoekstra D. Cationic lipid-mediated transfection in vitro and in vivo (review). Mol Membr Biol 2001; 18: 129-143.

46. Escriou V, Ciolina C, Lacroix F, et al. Cationic lipid-mediated gene transfer: effect of serum on cellular uptake and intracellular 
fate of lipopolyamine/DNA complexes. Biochim Biophys Acta 1998; 1368: 276-288.

47. Serikawa T, Suzuki N, Kikuchi H, Tanaka K, Kitagawa T. A new cationic liposome for efficient gene delivery with serum into cultured human cells: a quantitative analysis using two independent fluorescent probes. Biochim Biophys Acta 2000; 1467: 419-430.

48. Racoosin EL, Swanson JA. M-CSF-induced macropinocytosis increases solute endocytosis but not receptor-mediated endocytosis in mouse macrophages. J Cell Sci 1992; 102: 867-880.

49. Hewlett LJ, Prescott AR, Watts C. The coated pit and macropinocytic pathways serve distinct endosome populations. J Cell Biol 1994; 124: 689-703.
50. Dunglison GF, Kaye PL. Endocytosis in mouse blastocysts: characterization and quantification of the fluid phase component. Mol Reprod Dev 1995; 41: 225-231.

51. Hong K, Zheng W, Baker A, Papahadjopoulos D. Stabilization of cationic liposome-plasmid DNA complexes by polyamines and poly(ethylene glycol)-phospholipid conjugates for efficient in vivo gene delivery. FEBS Lett 1997; 400: 233-237.

52. Birchall JC, Kellaway IW, Mills SN. Physico-chemical characterisation and transfection efficiency of lipid-based gene delivery complexes. Int J Pharm 1999; 183: 195-207.

53. Crook K, McLachlan G, Stevenson BJ, Porteous DJ. Plasmid DNA molecules complexed with cationic liposomes are protected from degradation by nucleases and shearing by aerosolisation. Gene Ther 1996; 3: 834-839. 